\title{
Um almanaque de cidade como objeto de pesquisa da História da Cultura Escrita: Almanack da Parnahyba (1924-1982)
}

\section{A city almanac as research object of the history of written culture: Almanack da Parnahyba (1924-1982)}

\author{
Jeferson Luís Marinho de Carvalho* \\ Luciane Sgarbi Santos Grazziotin**
}

\begin{abstract}
RESUMO
Esse estudo diz respeito ao Almanack da Parnahyba, um livro de caráter periódico classificado como almanaque de cidade. Entendido como um documento histórico, a imersão em suas páginas possibilitou construir determinados aspectos vinculados à História da Cultura Escrita, circunscrita ao Piauí, na cidade de Parnaíba. A partir da análise do periódico, foi possível, por meio das características de sua materialidade e editoração, a compreensão de seu processo de edição, circulação e relação com o leitor. Observou-se que, no decorrer da temporalidade estudada, esse almanaque foi encontrado em distintos estados; sua presença ainda foi identificada em alguns países além do Brasil. Durante o período de sua publicação, atuou, direta ou indiretamente, como um difusor de ideais de civilidade, ancorado em um processo de discurso de modernização.
\end{abstract}

Palavras-chave: Cultura escrita. Almanaque. Produção de impresso. Circulação de impresso.

1 A discussão apresentada nesse artigo é um recorte inédito da tese de Jeferson Luís Marinho de Carvalho, Almanack da Parnahyba: leituras da educação em suas páginas (1924-1982), submetida à Universidade do Vale do Rio dos Sinos, em 2016.

* Instituto Federal de Educação, Ciência e Tecnologia do Piaú, Campus Parnaíba. Parnaíba, Piauí, Brasil. E-mail: jeferson@ifpi.edu.br. https://orcid.org/0000-0001-5807-5118.

** Universidade do Vale do Rio dos Sinos. São Leopoldo, Rio Grande do Sul, Brasil. E-mail: lusgarbi@terra.com.br. https://orcid.org/0000-0001-5648-3855. 


\begin{abstract}
This study concerns the Almanack da Parnahyba, a periodic book classified as a city almanac. Understood as a historical document, the immersion in its pages made it possible to construct some aspects as they are connected to the history of written culture in Piauí, more specifically in the city of Parnaíba. From the analysis of the almanac, it was possible, through the characteristics of its materiality, to understand its editing process, its circulation and relation with its readers. It was observed that, in the period investigated, the almanac could be found in different Brazilian states; moreover, its presence was identified in some countries other than Brazil. During its publication, the almanac functioned, directly or indirectly, as a voice of civility ideals, anchored in a process of modernization discourse.
\end{abstract}

Keywords: Written culture. Almanac. Production of printed material. Circulation of printed material.

\title{
Introdução
}

Verónica Sierra Blas, referindo-se às escritas epistolares, analisa a importância dos arquivos que se proliferaram na década de 1990 em distintos países da Europa. São acervos destinados à memória popular para "recuperar, salvaguardar, difundir e revalorizar os documentos produzidos por pessoas comuns" (SIERRA BLAS, 2016, p. 37).

Recorremos à análise da autora para refletir sobre outro documento, também escrito e produzido por pessoas comuns: um almanaque publicado na

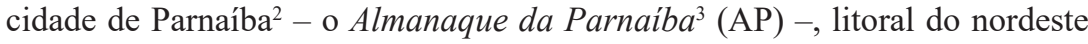
brasileiro. Sua importância se dá como elemento que visibiliza determinados aspectos relacionados à produção de um artefato impresso e seu processo de circulação, num conjunto de práticas que difundem um discurso de modernidade de uma cidade portuária do nordeste brasileiro.

Este estudo relaciona-se à cultura escrita e aos impressos cotidianos, questões que vêm, sistematicamente, assumindo um espaço significativo na produção

2 A cidade de Parnaíba fica localizada no norte do Estado do Piauí, na Mesorregião Norte Piauiense e na Microrregião Litoral Piauiense. Compreendida por uma pequena região litorânea banhada por um rio de nome Igaraçu, efluente do Rio Parnaíba, tem como divisas, ao norte, o Oceano Atlântico; ao leste, o Estado do Ceará; e, ao oeste, o Estado do Maranhão.

3 Embora originalmente tenha a grafia de Almanack da Parnahyba, no corpo do texto será utilizada predominantemente a grafia atual. 
historiográfica, sobretudo na História da Educação. O que tem permitido a compreensão de determinados discursos e representações acerca da educação, dos processos higienistas, de eugenia, de relações de gênero, de modernização, entre outros. A documentação utilizada foi localizada na Biblioteca Pública Municipal de Parnaíba, nas instalações do Instituto Histórico, Geográfico e Genealógico de Parnaíba (HGGP) e nos acervos articulares do senhor Diderot Mavignier e Sólima Genuína dos Santos.

No processo de garimpar esse arquivo, é imprescindível uma reflexão sobre a conservação dos documentos não oficiais e seu grau de efemeridade, uma vez que a conservação ocorre, de modo geral, por obra do acaso. Esses registros, em particular, foram abandonados em uma sala de aula de uma escola pública do município que a doou ao Instituto Histórico, Geográfico e Genealógico de Parnaíba.

A análise desse artefato, em suas distintas dimensões, permite circunscrever meio século de história do cotidiano da Cidade da Parnaíba, litoral do estado do Piauí. Trata-se de um cotidiano que indica, entre tantos aspectos possíveis de analisar, o processo de escolarização, as regras e etiquetas sociais, a literatura em voga, as práticas de escrita de seus cidadãos que, de diferentes maneiras, percorreram outros estados e países.

Foucault $(2008$, p. 7$)$ afirma que o fazer histórico na contemporaneidade está relacionado ao "[...] trabalho e à utilização de uma materialidade documental (livros, textos, narrações, registros, atas, edifícios) [...] que apresenta sempre e em toda a parte, em qualquer sociedade, formas de permanências, quer espontâneas, quer organizadas". A reflexão do autor corrobora essa dimensão de eventualidade e imprevisibilidade quanto àquilo que a sociedade mantém e quanto à possibilidade de transformar em documento alguns artefatos culturais.

O estudo desse periódico, repartido de outra maneira, como afirma Certeau (1982), transformou-se em documento, cujo objetivo, neste recorte, é analisar a materialidade do AP e seu processo de circulação. Para tanto, é fundamental compreender a gênese dessa tipologia de impresso, o suporte do almanaque em questão e a intencionalidade de seus editores.

\section{Origem e produção de "Almanaques"}

Com relação à palavra "almanaque" e às suas distintas formas de escrita são identificadas algumas interpretações ao longo do tempo; mas, em geral, todas remetem a um senso de contagem do tempo, de maneira habitual, baseando-se 
pela Lua. Com esse aspecto concordam dois autores da Literatura Brasileira, nomeadamente Machado de Assis ${ }^{4}$ e Eça de Queiroz ${ }^{5}$, que, no final do século XIX, escreveram contos que determinam a origem do artefato.

No registro historiográfico, atribui-se a origem dos almanaques ${ }^{6}$ ao Oriente; eram produzidos ainda de forma manuscrita e serviam de orientação para as comunidades antigas organizarem suas atividades laborais, sobretudo ligadas ao mundo agrário. No Continente Europeu, ao final da Idade Média, foram utilizados, em princípio, como uma forma de calendário que continha as principais atividades religiosas, além de dados astronômicos e diversas curiosidades.

No Brasil, a circulação dos almanaques se fez, inicialmente, de forma "clandestina"; eram então trazidos por colonizadores que para cá vieram. A partir da vinda da Família Real Portuguesa, houve autorização à produção de impressos, atividade até então proibida no país. O primeiro almanaque a circular no Brasil foi o Almanach Histórico do Rio de Janeiro (século XVIII), editado por Duarte Neves; cita-se também o "Almanaque para a Cidade da Bahia, ano 1812”. (PARK, 1998, p. 53).

No Piauí, a produção e a circulação de almanaques começam em 1879, com o Almanaque Piauiense (Almanach Piauhyense), em sua primeira fase, entre os anos de 1879 e 1882, publicado por Miguel de Sousa Borges Leal Castelo Branco. Era composto por dados estatísticos e notícias diversas (PINHEIRO FILHO, 1972). Outros almanaques publicados no Piaú foram o Almanack da Pharmacia dos Pobres, no ano de 1908, de propriedade do farmacêutico Thomaz Paz, em Teresina, e o Almanack para 1923, de Orlando Barbosa de Carvalho, em Oeiras. Há registros de outros que foram editados, mas que tiveram vida efêmera (MAVIGNIER; MOREIRA, 2007).

Esclarece Le Goff (1990) que existem diversos tipos de almanaques que foram surgindo e se espalhando pelo mundo em tempos e intensidades diferentes:

Ilustrado com signos, figuras, imagens, o almanaque dirige-se, sobretudo, aos analfabetos e a quem lê pouco. Reúne saberes astronômico, com os eclipses e as fases da Lua; religioso e social, com as festas e especialmente as festas dos santos que dão lugar aos aniversários no seio das famílias; científico e técnico, com conselhos sobre os trabalhos agrícolas, a medicina, a higiene; histórico, com as cronologias, os grandes personagens,

4 A obra se intitula "Como se inventaram os almanaques". (ASSIS, [1890] 2001).

5 Trata-se da introdução ao $1^{\circ}$ volume do Almanaque Enciclopédico (QUEIROZ, [1896] 2000).

6 Para mais informações sobre os almanaques, consultar: Rego (2010, p. 258); Le Goff (1990, p. 527); Anastácio (2012, p. 56); Correia e Guerreiro (1986, p. 47). 
os acontecimentos históricos ou anedóticos; utilitário, com a indicação das feiras, das chegadas e partidas dos correios; literário, com anedotas, fábulas, contos; e, finalmente, astrológico. (LE GOFF, 1990 p. 527).

Segundo o autor, em sua origem, os almanaques eram tidos, portanto, como uma produção de cunho popular, pois sua confecção, realizada com material mais barato, tornava seu preço acessível. Sua circulação abrangia as cidades, mas era grande sua presença no campo ou no "interior". Seus textos, organizados com muitas ilustrações, anedotas, curiosidades, dicas de saúde, religiosidade e instruções para diversos ofícios, agradavam aos leitores, desde os mais "letrados" aos menos "instruídos".

Tanto em sua origem, os escritos de Le Goff (1990) e de Correia e Guerreiro (1986) remetem ao discurso da simplificação, de um artefato que teria suas utilidades ao longo do tempo - inclusive aos menos esclarecidos, àqueles que não tinham acesso à leitura. A análise do AP fornece subsídios para problematizar essa discursividade com relação ao público leitor e aos espaços por onde circulava e, sobretudo, com relação ao seu conteúdo.

Esse estudo permitiu circunscrever determinadas idiossincrasias, presentes do processo de produção e circulação do $\mathrm{AP}$, com relação àquilo que se instituiu como norma de publicação dos almanaques de cidades, categoria no qual se enquadra.

\section{Almanaques de cidades}

Existem diferentes tipos de almanaques; ao longo da investigação, foram identificados alguns, como os de farmácias, de escolas, de jornais, do Brasil, dentre outros. Este estudo, no entanto, ater-se-á aos almanaques de cidades. Tais publicações, em especial, possuem uma estrutura bem diversificada, abordando desde os calendários, dias de santos, dicas para o dia a dia, literatura e biografias até dados estatísticos, históricos e geográficos da cidade que representam. À época de sua disseminação eram, muitas vezes, a única fonte de informações que a população tinha a respeito da localidade que habitava.

Ao contrário das revistas e dos jornais que tiveram vida efêmera, os almanaques de cidades, com uma periodicidade anual, perduravam por mais tempo. De modo que eles podiam, devido ao seu formato de livro, ser passados de mão em mão, ou lidos de forma coletiva, o que reduzia muito seu custo.

$\mathrm{O}$ AP, em virtude de suas características, foi enquadrado na categoria de almanaques de cidades. A publicação foi criada pelo que se pode considerar uma "elite intelectual" da cidade, à época que era formada, sobretudo, por 
profissionais liberais e comerciantes, com a intenção de produzir um discurso de progresso e civilidade com relação a uma localidade.

É possível perceber que esse artefato chegou às mãos das camadas populares tanto por meio da leitura individualizada de alguns poucos, em virtude da baixa escolarização da cidade, ou a partir da leitura coletiva, prática muito comum entre aqueles que possuíam pouco letramento ou viviam em áreas rurais. Algumas cidades, em princípio do século XX, tinham o AP como forma de divulgação de suas riquezas e realizações para a circunvizinhança.

A cidade de Parnaíba, na segunda década do século XX, já era uma cidade importante no Estado do Piauí. Sua riqueza esteve ancorada na charqueada, no couro bovino e nas salinas. Seus "filhos mais ilustres" participaram de diversos movimentos democráticos. Foi considerada "a primeira vila do Norte do Brasil a proclamar a independência, no dia 19 de outubro de 1822”. (MAVIGNIER; MOREIRA, 2007, p. 139).

Pretendendo suprir a lacuna de não ter um meio para divulgar a prosperidade da cidade e com o objetivo de integrar-se ao meio intelectual do município, o senhor Benedicto dos Santos Lima lança, em agosto de 1923, o primeiro livro impresso em Parnaíba: o então Almanack da Parnahyba. Apoiam e colaboram com a iniciativa os senhores Francisco Correia, Alarico da Cunha, Ranulpho Torres Raposo, Edison da Paz Cunha, entre outros que hoje emprestam seus nomes a muitas ruas e colégios na cidade.

O primeiro AP, em 1924, foi oferecido como uma forma de presentear amigos e fregueses da Mercearia Bembém. Esse costume é explicado por Andriès ao informar que os almanaques eram manuais práticos consultados pelas pessoas durante todo o ano. Tais publicações, geralmente, incluíam um calendário e, com frequência, eram oferecidas como presentes de ano novo. (ANDRIÈS, 1996, p. 287). Anastácio também reforça essa explicação ao enunciar que esse costume é bem antigo, uma vez que esses impressos continham "roteiros dos programas da ópera, dos teatros, e de outros divertimentos semelhantes destinados às elites, e o calendário", o que transformou os almanaques, do final do séc. XVII ao séc. XVIII, em objetos que eram trocados por pessoas da alta sociedade (ANASTÁCIO, 2012, p. 59-60).

Percebe-se que a publicação do AP era também um evento elegante, visto que, "Enquanto esteve dirigido por Bembém, o lançamento de cada edição constituía um acontecimento social, comemorado com banda de música e champagne, presentes as autoridades e personalidades locais" (PINHEIRO FILHO, 1972, p. 39). Esse fato, portanto, indica sua relevância naquele meio.

Cumprindo com o prognóstico anunciado em sua primeira edição, o AP é publicado por várias décadas, conforme sistematizado no Quadro 1. 
QUADRO 1 - QUANTITATIVO DA PUBLICAÇÃO DO ALMANAQUE DA PARANAÍBA (1924-2013)

\begin{tabular}{|l|l|c|c|}
\hline Período (ano) & $\mathrm{N}^{\circ}$ da Edição & Total de Edições & Responsável \\
\hline 1924 a 1941 & 1 a 18 & 18 & Benedicto dos Santos Lima \\
\hline 1942 a 1981 & 18 a 58 & 40 & Ranulpho Torres Raposo \\
\hline 1982 e 1985 & 59 e 60 & 02 & Manoel Domingos Neto \\
\hline 1994 a 1999 & 61 a 66 & 06 & APAL* \\
\hline 2004 & 67 & 01 & APAL \\
\hline 2006 & 68 & 01 & APAL \\
\hline 2013 & 69 & 01 & APAL \\
\hline
\end{tabular}

FONTE: Elaborado pelos autores com base no Almanaque da Parnaiba (2004, 2006 e 2013).

* Academia Parnaibana de Letras (APAL)

Uma possibilidade interessante de reflexão é compreender como foi possível sua manutenção por tantas décadas e como, em pleno século XXI, conseguiu competir com o mundo digital. Compreende-se, pelo seu conteúdo e público de interesse, que provavelmente não competiu com tais tecnologias, pois seus leitores eram outros.

\section{Materialidade do Almanaque da Parnaíba}

No processo de análise da materialidade do AP, de sua circulação e da relação com os leitores, é importante justificar como entendemos esse impresso. Krysztof Pomian destaca: “A obra literária é, pois, um objeto invisível, e o livro um objeto visível" (POMIAN, 1998, p. 72); assim, lidamos com o AP como obra literária e como livro.

Tanto quanto conteúdo, um objeto bibliográfico é também forma, é materialidade. Existem características materiais que os impressos periódicos apresentam e que devem ter a atenção do historiador, dado que sua materialidade permite ou restringe seu uso:

Um periódico, seja ele jornal ou revista, também veicula informações por meio de sua materialidade: tamanho, tipo de papel, qualidade de impressão, formato de suas folhas, uso de cores e imagens entre outros. [...] Assim, o uso de letras pequenas ou grandes, a organização em colunas ou em textos sem divisão, a encadernação, o tipo de papel, a capa, o uso de cores, a presença de fotos e figuras, o tamanho dos artigos/matérias, 
as características da linguagem utilizada, são elementos relevantes que contribuem, inclusive, para a caracterização do público à que o periódico se destinava. (TOLEDO; SKALINSKI JUNIOR, 2012, p. 263).

Conhecer essa materialidade do AP ajuda a compor sua própria história e a história de quem colaborou com a sua existência, sejam seus editores, seus escritores e, certamente, seus leitores. Um exemplo dessa importância é dado por Chartier ao esclarecer como se deu a produção dos livros da Bibliothèque Bleue:

Empregando caracteres usados, utilizando novamente madeiras gravadas que haviam sido abandonadas com o triunfo do talho-doce, imprimindo num papel ordinário, fabricados pelos papeleiros de Champagne, publicaram livros e brochuras de baixo preço, designados como "livros-azuis" - o que é uma alusão ao fato de que muitos deles (mas não todos) serem encapados de papel azul. (CHARTIER, 2002, p. 68).

Nessa pesquisa, Chartier analisa os possíveis usos de determinados textos, vinculando esses usos à materialidade do impresso, identificando distintas possibilidades de circulção de uma literatura considerada de elite.

Concebido como um livro de literatura geral, com espaço para poesias, contos, sonetos, biografias, fatos históricos e geográficos locais, nacionais e internacionais; dados estatísticos, de Parnaíba e do Piauí; além de muitos anúncios de empresas comerciais e industriais, bem como de produtos de vários lugares do Brasil, o AP assumiu várias funções. (CARVALHO; GRAZZIOTIN, 2015).

As características comuns aos textos eram dadas por critérios de seleção que obedeciam às determinações do seu editor, que anuncia:

COLABORAÇÃO: Qualquer pessôa que desejar colaborar para este anuario, deverá mandar os seus trabalhos até 15 de julho.

Somente aceitaremos trabalho que seja inedito ou especial para o Almanaque da Parnaíba. Recusaremos quaisquer matérias que já tenham sido publicadas. Trabalho para este genero de periodico deverá ser o mais curto possivel. (AP, 1933, p. 222).

Além dos textos, alguns aspectos da materialidade são apresentados na Figura 1, como a capa. 
A capa do almanaque é direcionada ao leitor; é uma parte da materialidade que circunscreve uma estética de época. Na primeira edição do AP (Figura 1, segmento a), a capa dá uma importante pista para a análise da intencionalidade dos seus editores; era uma publicação voltada para a "elite", o que implica um contraponto à discussão inicial, a qual indicava que os almanaques eram destinados à população menos letrada.

Nesse caso a publicação poderia e seria compartilhada por todos, cultos ou não, mas seus textos e ilustrações deixavam claro a quem, em princípio, era destinada. Nela, a representação de progresso ${ }^{7}$ está no desenho que retrata um casal, muito bem vestido, sentado a uma mesa da Mercearia Bembém, comendo e bebendo sem preocupações, talvez comemorando a passagem do "Ano Novo", ou celebrando o lançamento do próprio almanaque.

O AP foi editado no tamanho $16 \times 23 \mathrm{~cm}$ e manteve essa dimensão, salvo pouquíssimas alterações, em todas as suas edições seguintes. A primeira edição do AP continha 44 páginas e uma tiragem de 1.000 exemplares, que foram distribuídos aos fregueses e amigos da Mercearia Bembém no Natal de 1923. Editado de maneira consecutiva na forma de brochura $^{8}$, o AP procurou ser uma publicação de baixo custo.

Sua impressão era toda monocromática em $\mathrm{P} \& \mathrm{~B}^{9}$, à exceção da capa. Em algumas poucas edições, encontram-se páginas de fundo colorido em azul ou rosa e, em alguns exemplares a partir da década de 1940, a cor de algumas gravuras ou textos apareceu em azul, em meio ao tradicional preto (Figura 1, segmento b).

Seu modo de impressão foi a Relevografia, em especial a Tipografia ${ }^{10}$. Suas páginas apresentam, como padrão, a seguinte distribuição: páginas de numeração par, na maioria das vezes destinada às publicidades, e páginas de numeração ímpar, que apresentavam textos diversos. As páginas de textos apresentam-se divididas em duas colunas. Nas edições da década de 1920, essas colunas eram divididas por uma ornamentação central ou por colunagem ${ }^{11}$; sendo comum também apresentarem bordas ornadas (Figura 1, segmento c).

7 "O progresso da civilização, que o almanaque veicula em gotas para o leitor, parece depender dos 'homens superiores', assim como também parece ser um produto 'natural' do meio social”. (CASA NOVA, 1996, p. 131).

8 Livro de acabamento popular, costurado ou fresado, que recebe capa de papel cartão de alta gramatura colada diretamente no dorso. Cf. Collaro (2007, p. 145).

9 Classificação dada a originais em preto e branco. Collaro (2007, p. 149).

10 Impressão realizada mediante matriz em alto relevo. Os elementos que são impressos ficam em relevo na matriz e são entintados, imprimindo-se mediante pressão sobre o suporte. Processo hoje em desuso para a produção industrial de impressos. (OLIVEIRA, 2002, p. 37-38).

11 Divisão da página em módulos verticais que norteiam a disposição do texto nesse sentido. Cf. Collaro, (2007, p. 146). 
No início da década de 1940 (e nas edições até 1943), os textos eram diagramados em uma coluna. Entre as edições de 1944 e 1946, há uma mescla de textos em uma coluna com textos em duas colunas. A partir de 1947, passam a ser diagramados em uma única coluna e a apresentar layout mais sóbrio.

Até a edição de 1958, havia um cabeçalho ${ }^{12}$ em cada página do AP, identificando o ano, o nome do almanaque e a numeração da respectiva página. A partir da edição de 1950, aparece apenas a numeração da página na porção inferior. Também nota-se a ausência de um "sumário" até a edição de 1952; a partir de 1953, esse item passa a fazer parte das publicações do AP.

Outra característica interessante refere-se às imagens - fotos, desenhos, entre outros - usadas no AP. A maioria usava o sistema de clichê ${ }^{13}$ (Figura 1, segmento d), ou seja, a fotografia era esculpida em uma base de madeira que funcionaria como um "carimbo", atuando na impressão da imagem.

FIGURA 1 - ASPECTOS DA MATERIALIDADE DO ALMANAQUE DA PARNAÍBA

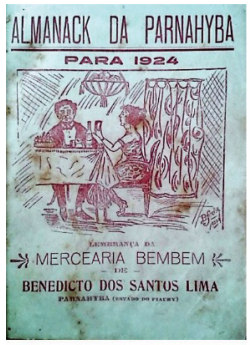

a)

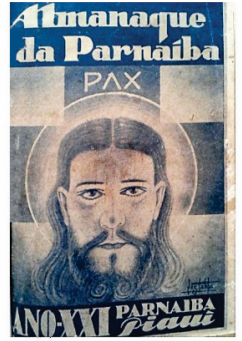

b)

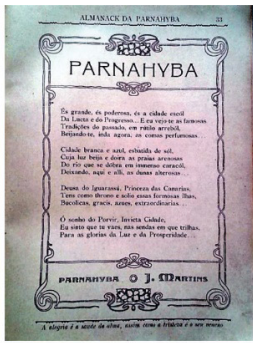

c)

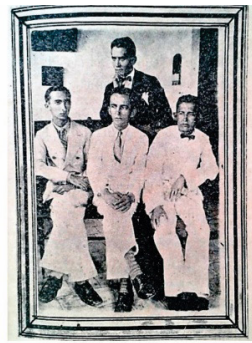

d)

FONTE: a) Almanack da Parnahyba (1924); b) Almanaque da Parnaíba (1944); c) Almanack da Parnahyba (1926); d) Almanaque da Parnaíba (1933).

NOTA: Da esquerda para a direita: a) Capa da primeira edição do Almanack da Parnahyba (1924); b) Exemplo de uso de cores na tipografia no Almanaque da Parnaíba (1944, p. 73); c) Exemplo de página com bordas ornamentadas no Almanaque da Parnaíba (1926, p. 33); d) Exemplo de um “clichê" no Almanaque da Parnaíba (1933, p. 75).

Não foi possível apurar qual foi a tiragem ${ }^{14}$ do AP, com exceção da primeira edição (1.000 exemplares), pois seu processo de impressão foi realizado por diversas tipografias e gráficas em diferentes cidades e estados. Essas tipogra-

12 Informação que identifica um periódico permanentemente, compreendendo o nome, a data de publicação, o ano, o número etc. Cf. Collaro (2007, p. 145).

13 Bases de ferro, alumínio ou madeira utilizadas na montagem dos clichês, estereotipias planas para a impressão tipográfica. Cf. Collaro (2007, p. 145).

14 Número de exemplares impressos de um determinado produto gráfico (COLLARO, 2007, p. 150). 
fias, em sua época, não possuíam registros de suas atividades e muitas já não existem mais.

A descrição da materialidade do AP chama a atenção para a disposição dos textos que eram distribuídos nas páginas de numeração ímpar. Tratava-se de textos curtos que, em consonância com o escopo dos almanaques, apenas introduziam um assunto, sem a profundidade que é comum aos livros. Essa característica era inclusive induzida pelo editor do AP, conforme estampado na seção "Expediente": "Não serão publicadas mais de duas composições de cada colaborador, cujos trabalhos não devem exceder de uma página, salvo quando se tratar de assunto histórico e biográfico, de interesses piauienses." (AP, 1934, p. 241).

No século XX, a ortografia brasileira passou por diversos acordos e reformas $^{15}$. A leitura do AP, no período de sua publicação, reflete bem essas mudanças, que faziam parte das preocupações dos seus editores, como pode ser evidenciado no seguinte trecho da edição de 1934: "Quanto à ortografia, preferimos a nova, posta em prática pela Academia Brasileira de Letras e oficializada pelo chefe do governo Provisório, contudo neste ano tivemos de obedecer ainda a dos originais". (AP, 1934, p. 241).

Sabemos que há outras opções para o exame da materialidade desse impresso. No entanto, entendemos que os aspectos aqui apresentados auxiliam na compreensão do processo de circulação e dos usos feitos por seus editores e leitores na temporalidade investigada.

\section{Circulação do Almanaque da Parnaíba}

A circulação de livros e outros impressos no Brasil, ao longo dos séculos XIX e XX, enfrentou diversos obstáculos, muitos dos quais ainda hoje permanecem. De forma oficial, a imprensa brasileira surge em 1808 com a "Imprensa Régia", mas os locais para leituras eram poucos. As raras bibliotecas existentes

15 “[...], apenas em 1915 a ABL aprovou um projeto do filólogo Silva Ramos, que ajustou a reforma brasileira aos padrões da portuguesa, de 1911. E, mesmo assim, ela ainda teria suas idas e vindas. 'Em 1919, o Brasil revoga, por indicação do acadêmico Osório Duque Estrada, tudo que tinha sido estabelecido em 1907', comenta Elis, referindo-se ao poeta parnasiano autor da letra do Hino Nacional Brasileiro. Em 1931, Brasil e Portugal enfim assinam um acordo. 'Depois de oficializado em 1933, o acordo de 1931 é derrubado pela Constituição brasileira de 1934, que mandava voltar à ortografia da Constituição de 1891. Só em 1938, a paz ortográfica é restabelecida, com a volta do acordo de 31', finaliza. Inicia-se, ali, um processo de uniformização da ortografia brasileira e portuguesa, que culminou em um novo acordo assinado em 1943”. (CUNHA, 2009). 
eram resultados comuns das iniciativas particulares de alguns professores, das quais o poder público mantinha-se afastado.

Havia dificuldades tanto para os leitores quanto para os autores nacionais; dentre esses aspectos, estavam a carência de canais adequados (tipografias e livrarias) e o analfabetismo, que registrava elevados índices. Além disso, o Brasil era influenciado pela valorização do "estrangeiro", com destaque para o que vinha da França, e o preço dos impressos era muito elevado.

Assim, o desenvolvimento de uma maior circularidade de livros e impressos no Brasil ficava condicionado ao desenvolvimento de novas bibliotecas, como também às oportunidades educacionais, melhor dizendo, a investimentos no sistema educacional do país. Dependia-se, contudo, de outros atores, como as determinantes políticas em cada época, o desenvolvimento ou os ciclos econômicos pelos quais a nação passava e, sobretudo, as condições sociais que estimulassem as práticas de leitura. Para Daniel Roche, "As práticas de leitura, a circulação do escrito, a produção de um discurso, oral ou impresso, consolidam as sociabilidades culturais". (ROCHE, 1998, p. 38).

No Piauí, a circulação dos impressos ficou, durante muito tempo, restrita à sua capital - primeiramente, Oeiras (1760 a 1852) e depois Teresina. Em comparação à capital Teresina, fica claro, pelas palavras de Pinheiro Filho, que a circulação de impressos em Parnaíba encontrava-se em estágio mais avançado. $\mathrm{O}$ autor explica:

Acontece que Parnaíba teve oportunidade de possuir jornais antes mesmo de Oeiras e Teresina, devido ao empório comercial que representava, e a ligação marítima com as demais províncias e depois Estados do Brasil, e países do mundo. Não sentiu, porém, esta necessidade, pois, que ali se recebiam regularmente jornais do Maranhão, de Pernambuco e da Corte. (PINHEIRO FILHO, 1972, p. 39).

É preciso salientar que a circulação de livros, jornais, folhetos, relatórios diversos, revistas e almanaques era restrita às camadas sociais dominantes, tanto para os leitores quanto para os autores. Estes, por sua vez, eram formados, em sua maioria, por professores, jornalistas, editores de revista e jornais.

Quanto à circulação específica do AP, não foram encontrados documentos escritos, mas foi possível, por meio de um olhar atento às páginas do almanaque, identificar alguns dos locais por onde a publicação circulou ao longo do período estudado, aspecto registrado pelos prórpios editores. Diante disso, o ideal é continuar a investigação para determinar os caminhos percorridos pelo almanaque. 
É possível observar, por meio de um anúncio em que a publicação abre espaço para novos anunciantes, que o almanaque aproveita para apresentar os diversos lugares por onde tem circulação.

Anuário de grande tiragem, com vasta circulação em todo o País, principalmente nos Estados do Piauí, Ceará e Maranhão, tornando-se por tais motivos, o mais eficiente veículo de propaganda.

Anunciar no "ALMANAQUE DA PARNAÍBA" é ter a segurança de excelentes resultados, pois se trata de uma publicação valiosa, que se conserva nas estantes, para consulta e leitura frequentes. (AP, 1957, p. 150).

Além do território brasileiro, são relacionados dois continentes, Europa e América, com destaque para New York, na América do Norte. Na Europa são citados países como Portugal, França, Alemanha e Inglaterra. É algo notável que uma publicação com apenas dez edições tenha alcançado, na década de 1930, uma abrangência territorial tão ampla. Seria isso fato? E como isso poderia ser possível?

Embora as afirmações, quanto à sua circulação recomende cautela, esses espaços identificados como lugares de circulação do AP são perfeitamente possíveis, uma vez que Paranaíba era porta de entrada para diferentes mercadorias e servia de escoadouro dos produtos da pecuária e do extrativismo vegetal dos estados do Ceará, Piauí e Maranhão. Além disso, seu editor tinha vínculo com tais atividades comerciais e, portanto, interesse em divulgar a movimentação econômica da cidade. Esses aspectos tornam possível, em certa medida, entender alguns elementos que indicam sua presença em cidades e países distantes. Desse modo, entendemos que o AP poderia acompanhar a circulação das mercadorias e "viajar na carona" dos representantes comerciais oriundos de outros lugares.

Outra forma de mapearmos a circulação do AP é por intermédio das transcrições que noticiaram o lançamento de cada edição. Pelo observado, era comum o editor do AP enviar exemplares para diversos jornais no país como forma de divulgação nessa mídia impressa. No texto "Como foi recebida à edição de 1956 do "ALMANAQUE DA PARNAÍBA", publicado em 1957, é reproduzida uma nota do Jornal do Brasil ${ }^{16}$ e de $O$ Estado, dos quais são transcritos alguns trechos a seguir:

16 Fundado em 1891 no Rio de Janeiro, o Jornal do Brasil, a partir de 1956, passa por uma reformulação editorial e gráfica, adotando o chamado "jornalismo literário", inclusive com a criação de uma página literária intitulada "livros e autores contemporâneos", assinada por Reynaldo Jardim. Mais informações disponíveis em: <www2.dbd.puc-rio.br/pergamum/tesesabertas/0410535_06_cap_03.pdf>. 
Do Jornal do Brasil:

Excelente, sem dúvida, em seu gênero, é o "Almanaque da Parnaíba", publicação que, há 33 anos, vem sendo editada em Parnaíba, Estado do Piauí. Dirigido pelo Sr. Ranulfo Torres Raposo, o "Almanaque da Parnaíba" reúne todos os requisitos capazes de o tornarem interessante e útil, seja pela variedade de matérias que anualmente reúne e divulga, seja pela cuidadosa seleção de assuntos utilizados [...].

Em O Estado, Carlyle Martins escreve:

Como das vezes anteriores, apresentou-se o "Almanaque da Parnaíba", correspondente ao ano de 1956, com ótima feição material, referto de colaborações de primeira ordem e com um serviço informativo dos mais abundantes e completos. (AP, 1957, p. 253).

O percurso do AP, para além da cidade, também pode ser explicado pela origem ou residência de seus colaboradores que enviavam textos de vários estados do Brasil. Na leitura do almanaque, identificamos autores de diferentes localidades, com destaque para Piauí, Ceará, Maranhão, Pará e Amazonas. Também é possível citar Pernambuco, São Paulo e Rio de Janeiro, pois, nos jornais da época dessas cidades, encontram-se indícios como o encontrado na Folha de São Paulo do dia 16 de março de 1980, no qual é possível ler: "começa a ser distribuido o número 58 do mais antigo anuário literário do País, o 'Almanaque da Parnaíba'. Publicado no Piauí com a colaboração de escritores de todo o Brasil. O 'Almanaque’ existe desde 1924 e é editado até hoje pelo seu fundador, Ranulpho Torres Raposo.” (AP, 1981, p. 301).

\section{Considerações finais}

Pelo estudo realizado, quanto à circulação do AP, podemos perceber que várias são as pistas que indicam alguns dos caminhos percorridos por essa publicação dentro e fora do País. Os aspectos considerados até o momento permitem refletir a respeito dessa circularidade. 
Ao analisar o processo de circulação do AP, por meio de sua materialidade, foi possível percebê-lo como uma publicação de circulação expressiva na cidade de Parnaíba entre os anos de 1924 e 1982, verificando que o almanaque teve significativa circulação em outros estados. Além de alguma maneira, o almanaque ter circulado em outros países, fato atribuído à localização de Parnaíba e à mobilidade comercial permitida pelo porto da cidade.

Esse conjunto de elementos relacionados à materialidade e à circulação do AP, presentes nas imagens e nos textos selecionados, permitem compreender algumas das intenções de seus editores. Esses elementos estavam relacionadas à divulgação de uma cidade, de sua modernização e de seu progresso e desenvolvimento econômico, com o objetivo de atrair investidores e novos moradores.

Reiteramos que o foco deste artigo foi fazer um breve panorama dos aspectos de materialidade e circulação do Almanaque da Parnaíba, dessa forma foi possível perceber, de modo geral, como a manifestação da cultura escrita, representada no almanaque pode, por meio da sua circulação, alcançar diferentes espaços, sejam geográficos ou sociais, ao longo de uma temporalidade que permeou gerações. No entanto, cada um desses aspectos, possivelmente, poderia se constituir em pesquisas isoladas, constituindo-se em investigações que os analisariam com maior profundidade.

\section{REFERÊNCIAS}

ANASTÁCIO, V. Almanaques: origem, géneros, produção feminina. Santiago de Compostela: VEREDAS 18. Associação Internacional de Lusitanistas, 2012. p. 53-74.

ANDRIÈS, L. Almanaques: Revolucionando um gênero tradicional. In: DARNTON, R.; ROCHE, D. (Orgs.). Revolução Impressa: A Impressa na França (1775-1800). São Paulo: Edusp, 1996. p. 287- 307.

ASSIS, M. de. Como se inventaram os almanaques. In: MEYER, M. Do Almanak aos Almanaques. São Paulo: Ateliê Editorial, 2001 [1890]. p. 25-28.

CARVALHO, J. L. M. de. Almanack da Parnahyba: leituras da educação em suas páginas (1924 -1982). 2016. Tese (Doutorado em Educação) - Universidade do Vale do Rio dos Sinos, São Leopoldo (RS), 2016.

CARVAlHO, J. L. M. de; GRAZZIOTIN, L. S. Santos. Almanaque da Parnaíba e a instrução pública no Piauí de 1924 a 1940 In: DÍAZ, José María Hernández (Org.). La Prensa de Los Escolares y Estudiantes su contribuición al patrimonio histórico educativo. V. 1.1 ed. Salamanca: Ediciones Universal Salamanca, 2015. p. 7-972. 
CASA NOVA, V. Lições de Almanaque - um estudo semiótico. Belo Horizonte: Editora UFMG, 1996.

CERTEAU, M. de. A Escrita da história. tradução de Maria de Lourdes Menezes, revisão técnica [de] Arno Vogel. Rio de Janeiro: Forense Universitária, 1982.

CHARTIER, R. Os desafios da escrita. São Paulo: Editora UNESP, 2002.

COLlaro, A. C. Produção gráfica: arte e técnica da mídia impressa. São Paulo: Pearson Prentice Hall, 2007.

CORREIA, J. D. P.; GUERREIRO, M. V. Almanaques ou a sabedoria e as tarefas do tempo. Revista ICALP, v. 6, p. 43-52, ago./dez. 1986.

CUNHA, M. T. S. Diários pessoais: territórios abertos para a história. In: PINSKY, C. B.; DE LUCA, T. (Org.). O historiador e suas fontes. São Paulo: Contexto, 2009. p. 251-279.

FOUCAULT, M. A arqueologia do saber. Tradução de Luiz Felipe Baeta Neves. 7. ed. Rio de Janeiro: Forense Universitária, 2008.

LE GOFF, J. História e memória. 4. ed. Campinas, SP: Editora da UNICAMP, 1990.

MAVIGNIER, D. dos S.; MOREIRA, A. M. Conhecendo história e geografia do Piauí. Parnaíba: Gráfica Ferraz, 2007.

OLIVEIRA, M. Produção gráfica para designers. 2. ed. Rio de Janeiro: 2AB Editora, 2002.

PARK, M. B. Histórias e leituras de almanaques no Brasil. 1998. Tese (Doutorado em Educação) - Programa de Pós-Graduação em Educação, Universidade Estadual de Campinas, Campinas (SP), 1998.

PINHEIRO FILHO, C. História da imprensa no Piauí. Teresina: COMEPI, 1972.

POMIAN, K. História cultural, história dos semióforos. In: SIRINELLI, J.-F. Para uma história cultural. Lisboa: Editorial Estampa, 1998. p. 71-95.

QUEIROZ, E. Notas Contemporâneas. Lisboa: Livros do Brasil, 2000 [1896].

REGO, J. M. A. N. do. Dos sertões aos mares: História do comércio e dos comerciantes de Parnaíba (1750-1950). 2010. Tese (Doutorado) - Programa de Pós-Graduação em História, Universidade Federal Fluminense, Niterói, 2010.

ROCHE, D. Uma declinação das luzes. In: RIOUX, J.-P.; SIRINELLI, J.-F. Para uma história cultural. Lisboa: Editorial Estampa, 1998. p. 25-50.

SIERRA BLAS, V. Cartas Presas: la correspondência carcelaria em la Guerra Civil y el Franquismo. Madrid: Marcial Pons Historia, 2016.

TOLEDO, C. de A. A. de; SKALINSKI JUNIOR, O. A imprensa periódica como fonte para a história da Educação: teoria e método. Revista HISTEDBR On-line, Campinas, n. 48 , p. $255-268$, dez. 2012. 


\section{Fontes}

ALMANACK DA PARNAHYBA (AP). Ano I. Fortaleza, Ceará: Typographia Renascença, 1924.

ALMANACK DA PARNAHYBA (AP). Ano III. Belém, Pará: J. B. dos Santos e Cia, Livreiros Editores, 1926.

ALMANAQUE DA PARNAÍBA (AP). Ano IX. Fortaleza, Ceará: Typographia Gadelha, 1933.

ALMANAQUE DA PARNAÍBA (AP). Ano XI. Parnaíba, Piauí: Gráfica Renascença, 1934.

ALMANAQUE DA PARNAÍBA (AP). Ano XI. Parnaíba, Piauí: Gráfica Renascença, 1944.

ALMANAQUE DA PARNAÍBA (AP). Ano XXXIV. Fortaleza, Ceará: Oficinas do Almanaque da Parnaíba, 1957.

ALMANAQUE DA PARNAÍBA (AP). Ano LVIII. Fortaleza, Ceará: Gráfica Editorial Cearense, 1981.

ALMANAQUE DA PARNAÍBA (AP). 1ed. v. 69. Parnaíba: Gráfica e Editora Sieart, 2004.

ALMANAQUE DA PARNAÍBA (AP). Revista da Academia Parnaibana de Letras. n. 69. Parnaíba: Gráfica e Editora Sieart, 2006.

ALMANAQUE DA PARNAÍBA (AP). Revista da Academia Parnaibana de Letras, ed. 70. Parnaíba: Gráfica e Editora Sieart, 2013.

ALMANACK DA PARNAHYBA. Ano I. Fortaleza, Ceará: Typographia Renascença, 1924 a 1982.

Texto recebido em 12 de julho de 2017. Texto aprovado em 12 de fevereiro de 2018. 
